\title{
Instilling the Awareness of Environmental Conservation Through Unobserved Environmental Physics Concepts
}

\author{
Henny Johan ${ }^{1 *}$, Bhakti Karyadi ${ }^{1}$, Agus Sundaryono ${ }^{1}$ and Sipriyadi ${ }^{2}$ \\ ${ }^{I}$ Magister of Science Education, Bengkulu University, Indonesia \\ ${ }^{2}$ Department of Biology, Faculty of Mathematics and Natural Sciences, Bengkulu University, Indonesia \\ *Corresponding author. Email: hennyjohan@unib.ac.id
}

\begin{abstract}
The science concepts are related to our daily lives and to the environment around us. This research aimed to instill the awareness of environmental conservation through unobserved environmental physics concepts. This research used experimental research with one group only post-test design. 15 postgraduate students of science education participated in this research. Questionnaire and open-ended questions were used to collect data about students' responses and students' assumption related to instilling of the awareness of environmental conservation. The data was analyzed quantitatively. The results of data analysis derived from the open-ended question verify that the learning activity by visualizing the unobserved environmental physics concepts can help to understand the concept, to instill the awareness of environmental conservation and spiritual value. The awareness of environment and spiritual values can be explored in relation to the environment, creation, and preservation of the environment. Media animations in environmental physics lectures can open insights on how to preserve the environment. It can be concluded that the awareness of environmental conservation and spiritual value can instilled through visualizing unobserved environmental physics concepts.
\end{abstract}

Keywords: Conservation, Physics environmental, Awareness of Environmental, Unobserved Concepts.

\section{INTRODUCTION}

Various scientific concepts have characters that cannot be directly observed (unobservable) so students have difficulty understanding the concept [1],[2],[3]. The science concepts are related to our daily lives and to the environment around us. Media that can visualize various unobservable concepts is very necessary. The media used can help understand concepts more easily. By visualizing various science concepts related to the environment around us, students can understand the concepts well [4]. Visualization of unobservable concepts helps them to analyze environmental conditions using an understanding of science concepts related to environmental physics.

The use of teaching materials accompanied by the media to visualize the concepts of environmental physics that cannot be directly observed is very necessary to help instill awareness of the importance of caring for the environment. Animation media can be used to facilitate students to understand science concepts more easily and to relate science concepts with environmental conditions from various aspects and points of view. The widespread environmental damage can be seen from the standpoint of science concepts macroscopically and microscopically. Microscopic review certainly involves knowledge related to unobservable scientific concepts. One example of the concept of environmental physics that requires explanation through the concept of physics with microscopic character and cannot be directly observed is the phenomenon of global warming in Figure 1.

The interrelationship of science concepts and phenomena that occur in our daily environment can also be explained from a microscopic perspective. This is expected to instill awareness for environmental concerns. Various facts reveal a lot of environmental destruction. This inflicts a direct or indirect impact on human life. From a macroscopic perspective, it is certainly not difficult to understand the relationship 
between science concepts and environmental conditions. Presenting facts related to natural damage can be used to instill awareness of environmental care. By visualizing the microscopic concept and the interrelationship between science and the environment, it is also expected to be used to secure awareness of environmental concerns. Environmental care needs to be strengthened through the learning of scientific concepts. This is because the concept of science is related to environmental phenomena. Various media to visualize environmental physics concepts can instill awareness of the importance of caring for the environment.

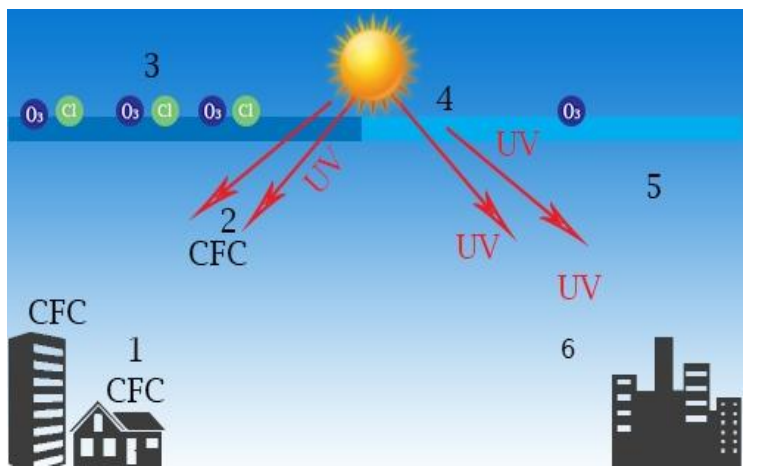

(a)

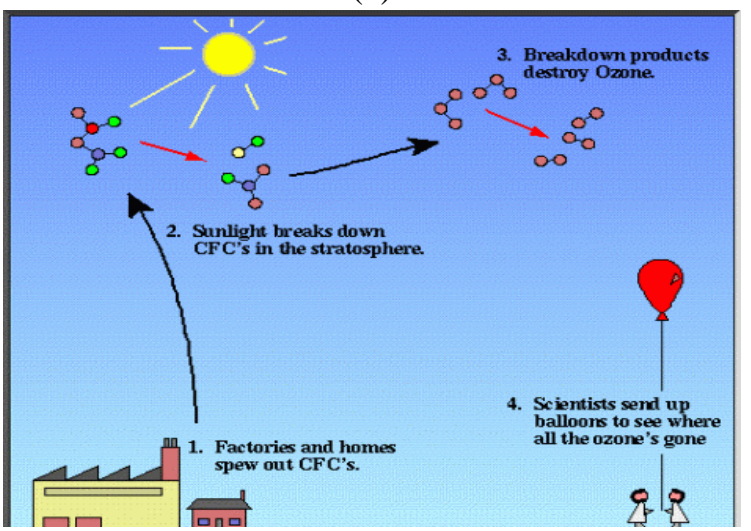

(b)

Figure 1 (a) and (b) Microscopic concepts of global warming phenomenon. (Source: national.okezone.com)

\section{METHOD}

\subsection{Research Design}

Pre experimental with one group post-test design was implemented in this research. Before treatment, concepts were analyzed to identify the visual media that relevant to the concepts. Media visualization could visual the process and step of an environmental phenomenon. This phenomenon can be explained by physics science concepts including physics environmental concepts. The student engaged to construct the concept interactively with help of media visual that visual the concepts related to the environmental phenomenon. In addition, the concern for the environment is instilled through the process of visualizing microscopic concepts related to the environment. Students were also engaged to find correlation among concepts to the causes of environmental damage. Questions and feedback were done along with learning activity. Classroom interactive by using questions and feedback was presented to stimulate student awareness to the environment. Students were given open-ended questions to explore the value of environmental phenomena.

\subsection{Research Subject}

In this research, there were 5 postgraduate of science education students involved. Research subject have never taken physic environmental course before. Convenience sampling was carried out in this research.

\subsection{Instrument Collecting Data}

For collecting data, some instruments were constructed. Two types of instruments in collecting data were developed. It includes a questionnaire and openended questions. Questionnaire and open-ended questions were used to collect data about students' responses and students' assumptions related to instilling the awareness of environmental conservation.

\subsection{Data Analysis}

Students' responses from open ended and questionnaire were analyzed qualitatively. That coded to find the pattern of the responses about the learning process. Some important points related to instilling environmental awareness in this study include:

1. The concept of physics is related to the environment

2. Visualization media helps to understand the concepts of environmental physics that cannot be directly observed

3. Animation media can help understand the factors that influence the environment

4. Spiritual values related to the concepts of environmental physics, creation, and preservation of the environment

5. How to behave towards the environment

\section{RESULTS AND DISCUSSION}

After the learning activities use visual media to present the invisible concepts of phenomena related to environmental physics, data are obtained from questionnaires and open-ended questions. In the questionnaire, the data were collected regarding to the students' opinions of learning activities and its impact on awareness of environmental care, instilling spiritual value through the concept of environmental physics. The results of the questionnaire show that all students testified that physics environmental course by visualizing unobservable concepts can facilitate to understand the concepts of environmental physics because it can display details of concepts related to environmental phenomena. This is synergy with 
qualitative data on student responses in the open-ended questions instrument. Students stated that the animation media was very helpful in understanding the concepts of environmental physics. On the other hand, the students are also able to give examples on how the concept of physics environmental can impact their spirituality and their awareness of environmental care. Student responses to the open-ended question can be seen in Figure 2.

Based on figure 2, it can be known that students can explain the details of the process of the orographic rain. It shows that the use of visualization media such as animation is able to practice the student's ability of multiple representations, especially image or chart representations. Students explain the unobservable process of rain orography which not only uses verbal representations but is also made clear using image representations. This result is also supported by student's response as following

Figure 3 "From 2 types of rain animation, I can understand the process and distinguishes from the 2 types of rain (orographic rain and convergence) easily than verbal explanation only. Of course with the addition of animation media certainly makes it easier to understand the environmental physics concepts."
The results of data analysis derived from the openended question verify that student can:

1. Explain the relationship between physics concepts and the environment and then explain the contribution of visualization media in understanding the concepts of environmental physics.

2. Explain how the media animations help students to understand the factors that affect the environment.

3. Explain the spiritual values that can be explored in relation to the environment, creation, and preservation of the environment.

4. Explain and exemplify the appropriate actions to be taken relating to the environment.

5. Explain and exemplify how animation media in environmental physics lectures can open insights on how to preserve the environment.

6. Explain why it is important to care about the environment

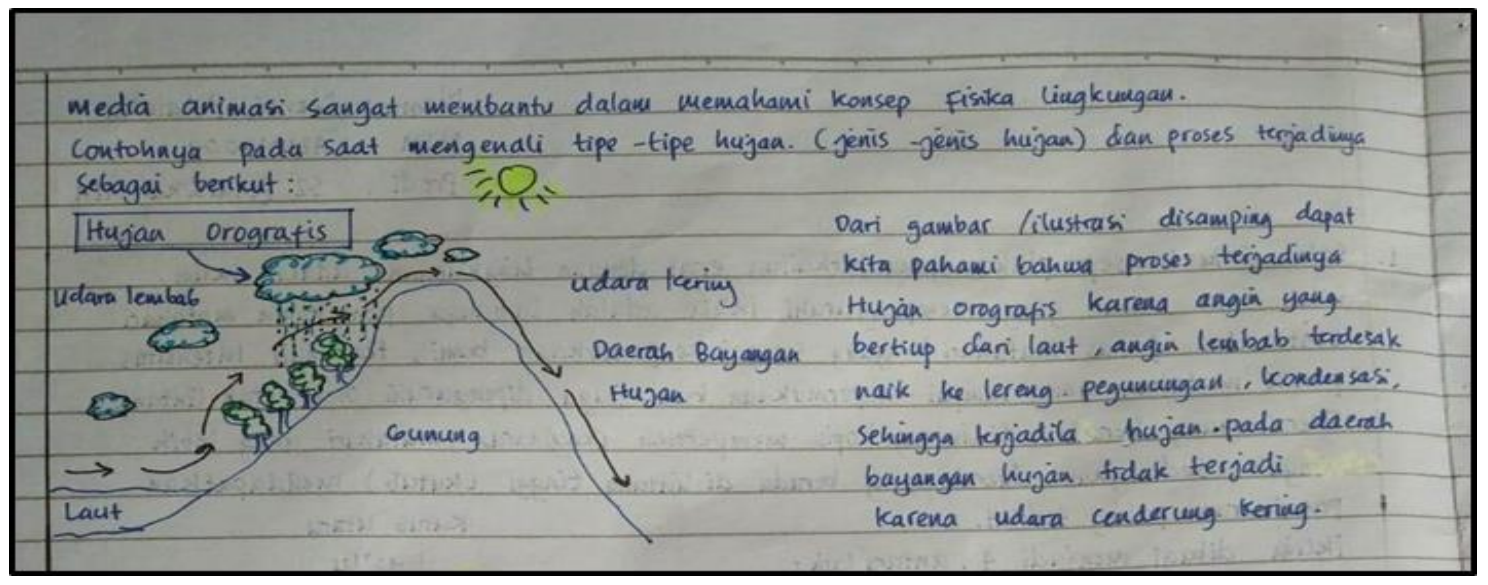

Figure 2 Student responses related to the contribution of unobservable concept visualization through animation media in understanding the concepts of environmental physics.

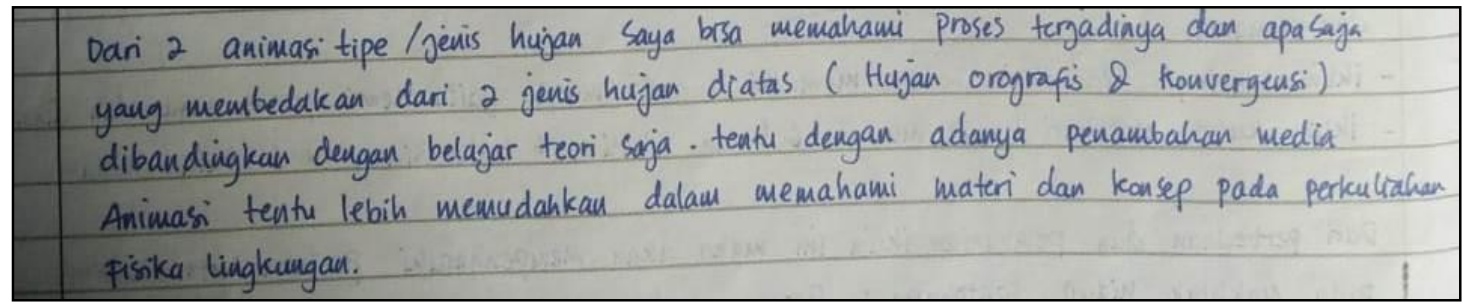

Figure 3 Student responses related to the contribution of unobservable concept visualization through animation media in understanding the concepts of environmental physics. 


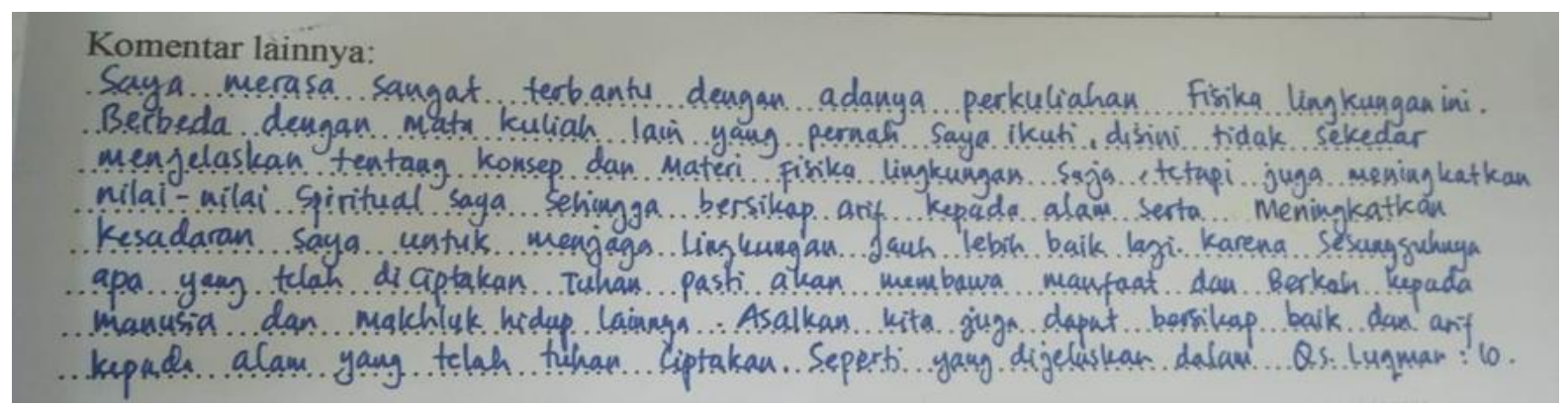

Figure 4 Student responses stating that lectures on environmental physics assisted by visualization media that have been carried out can instill spiritual values and also awareness of care for the environment.

Based on the data in the open-ended question, it can be seen that according to students of environmental physics lectures that have been carried out assisted by visualization media, it has an impact on environmental fundamental physics teaching materials.

Figure 4 shows that according to students of environmental physics lectures using visual media to visualize various natural phenomena related to environmental physics can help understand the concepts of environmental physics be able to instill spiritual values. It also could instill a sense of awareness of the importance of protecting the environment.

The results of this study are synergized with research that has been done by [5],[6]. that research results show that learning earth science using the media visualizations can improve understanding of their concepts for example in the concept of an earthquake. The benefits of visual media, especially video animation used in learning activities that have been carried out, are supported by the results of research by Kortz and Kraft which shows that animation can help understand geology concepts more easily[7]. Johan states that media visualization is also able to display the modeling of authentic data to explain many natural phenomena [9].

The results of the study also support the statement of Varutharaju \& Ratnavadivel who revealed that visualization in the form of simulations used in learning activities facilitates the ability to think highly so that cognitive abilities can be achieved properly [8]. Johan et al state that IPBA learning activities assisted with unexpected animation media apparently also support the analogy thinking process [5] [9]. Ainsworth stated that the advantages of using representation in learning activities are facilitating the thinking process and reasoning activities [10]. Findings from the results of this study indicate that learning designed with the aid of visualization media has an impact on the development of the ability of visual representation especially in the form of drawings or sketches. This finding is relevant to previous research by Johan [11]. The result of the study found that media visual facilitate to stimulate the multiple representation skill especially in the form of drawings or sketches [11]. This can be seen in the response of students as shown in Figure 2. In Figure 2, it can be seen that students use image representation in explaining the process of the occurrence of orographic rain which affects the environment around the slope.

The earth phenomenon presented with the help of animated media in learning activities using impacts:

1. Facilitate students thinking skills about the relationship (cause and effect) between concepts.

2. Animation is very clear, very helpful in making it easier to reason concepts and then understanding concepts because IPBA learning really requires reasoning, imagination because it cannot be observed directly, the animation displayed is very clear.

3. Complex concepts are made easier because visualization of the concept is seen [12] [13] [14]. The earth phenomena that are displayed through the help of visual media in addition to helping in developing the ability to reason can also facilitate the strengthening of spiritual attitudes related to belief in the nature of God. Visual media help display the process of occurrence of natural phenomena (related to the IPBA concept) that cannot be observed directly. Strengthening the attitude of trust towards the nature of God is also done through a process of reasoning [15]. In addition to spiritual attitudes, the presentation of natural phenomena using animation can also strengthen the exception attitude to the environment because through animation media an unobservable process can be presented on a phenomenon and its impact on the environment. Previous study found that media visualization also able to display the process of natural disasters to instill the awareness of mitigation [16].

\section{CONCLUSION}

Based on the analysis of findings, it can be concluded that learning the awareness of environmental conservation and spiritual value can be instilled through visualizing unobserved environmental physics concepts. Presentation of natural phenomena using animation can also strengthen the exception attitude to the environment because through animation media an unobservable process can be presented on a phenomenon and its impact on the environment. The 
results verify that student can explain the relationship between the physics concepts and the environment and then explain the contribution of visualization media in understanding the concepts of environmental physics, explain how the media animations help students to understand the factors that affect the environment, explain the spiritual values that can be explored in relation to the environment, creation and preservation of the environment, and explain or exemplify how animation media in environmental physics lectures can open insights on how to preserve the environment.

\section{ACKNOWLEDGMENTS}

The authors thank to Septi Johan, M.Si and all parties that gave contribution for collecting data in this study.

\section{REFERENCES}

[1] King, Chris Jhon Henry, International Journal of Science Education, 2010, 32(5) 565-601.

[2] Miller, Brian W, and W F Brewer 2010 International Journal of Science Education 32(12) 1549-1560.

[3] Park, Su-Kyeong Eurasia Journal of Mathematics Science \& Technology Education, 2013, 9(3) 285-299.

[4] Smith G. A. and Bermea S. B., Journal of Geoscience Education, 2012, 60(4) 350-359.

[5] Johan H, A. Suhandi, A R Wulan, and Sipriyadi Journal of Turkish Science Education, 2018, 15(1) 109-127.

[6] Johan H, A Suhandi, A R Wulan, Sipriyadi, A Herawati. Jurnal Pendidikan IPA Indonesia, 2018, 7(4) 435-441.

[7] Kortz K M and KJ van der Hoeven Kraft, Journal of Geoscience Education, 2016, 64(1) 24-36.
[8] Varutharaju E. and N. Ratnavadivel Malayan Journal of Learning and Instruction, 2014, 11: 75-100.

[9] Johan, H., Suhandi, A., Wulan, A. R., Ruyani, A., \& Karyadi, B. (2018, May). Embedding spiritual value through science learning. In Journal of Physics: Conference Series (Vol. 1013, No. 1, p. 012083). IOP Publishing.

[10] Ainsworth S, Journal of Computers and Education, 1999, 33: 131-152.

[11] Johan H, A Suhandi, A R Wulan, Sipriyadi Jurnal Pendidikan Fisika Indonesia, 2018, 14(1) 7-17.

[12] Johan H, A Suhandi, and A.R. Wulan, Proceeding National Seminar of SNIPS Bandung Indonesia, 2016, 385-389.

[13] Johan H, Suhandi, A., and Wulan, A. R. Proceedings International Seminar on Mathematics, Science, and Computer Science Education, 2017, 175-181.

[14] Johan, H., Suhandi, A., Samsudin, A., \& Wulan, A. R. (2017, September). Applying Authentic Data Analysis in Learning Earth Atmosphere. In J. Phys.: Conf. Ser (Vol. 895, p. 012099).

[15] Johan H, A. Suhandi, A. Samsudin, and A. R. Wulan. . AIP Conference Proceedings, 2017, $1868,080004$.

[16] Johan, H., Swistoro, E., Rohman, S., Parlindungan, D., \& Sipriyadi, S. (2019, April). Constructing the Test for Describing the Students' Problem Solving Skill to Mitigate the Earthquake Disaster. In International Conference on Educational Sciences and Teacher Profession (ICETeP 2018). Atlantis Press. 